\title{
NEW ENGLISH WORDS FOR DESCRIBING THE INTERNATIONAL ENGLISH AS A CURRENT WORLD LANGUAGE REALITY
}

\author{
NATALIA K. IVANOVA \\ Ivanovo State University of Chemistry and Technology, Ivanovo, Russia \\ nkiisuct@mail.ru
}

NADEZHDA E. MERKULOVA

Ivanovo State University of Chemistry and Technology, Ivanovo, Russia srg69@bk.ru

\begin{abstract}
The evolution of the English language, its changing in the situation of language contacts and functioning of English as an international means of communication have created a need for a more systematic analysis of related phenomena. In this paper, new English words which apparently appeared due to globalization and internationalization, have been considered. On the basis of authoritative theoretical approaches and several e-dictionaries, the words selected by means of continuous sampling method (more than 200 units) were analysed in terms of their semantics, morphology and spelling. Then they were classified into several thematic groups: 1) new words for naming natural and artificial versions of current English; 2) words classified with regard to social accents and dialects; 3 ) neologisms that reflect the English language domain and its interaction with indigenous languages. The morphological analysis revealed the application of different processes of word-formation, including neologisms and forms created according to traditional English patterns. Sometimes play on words and homo-acronyms were used in order to reinforce the meaning and connotation. Compounding and blending were found to be the most productive means of words formation within the corpus, and stylistic neologisms, used to mark a certain underlying sense proved to be the second most frequent process. It is demonstrated that studying of the currently active processes of word formation in the English language used as an international communication tool emphasizes the interdisciplinary aspect of such research programs.
\end{abstract}

Keywords: English as an international language, lexicography, lexicology, neologism, lexical semantics

\section{International English and a phenomenon of new words}

The English language functioning as an International (global) means of communication for people of different linguistic and cultural backgrounds have encouraged numerous researchers from many countries to conduct profound interdisciplinary studies over the years. At present, several approaches for 
describing English as an international communication medium exist. There are two main paradigms based on the opposition of centrifugal and centripetal trends in the spread of English in the world. The first one is World Englishes (WE) based on Kachru's (1986) description of institutionalized varieties of English and focused on the ideas of pluricentricity of the English language and diversity of its variants in national, regional, and idiolectal levels. The second approach relates to English as an International Language (EIL), which is supposed to be a neutral, universal language variety. Both of them were the objects of comprehensive investigations (Halliday, McIntosh, Strevens 1964; Smith 1976, 1981; Kachru 1986; Firth 1996; House 1999; Schneider 2003, 2007; Seidlhofer 2005; Jenkins 2009; Kirkpatrick 2010, 2011; McKay, Bokhorst-Heng 2017). However, the plethora of terminology and incompatible approaches in determining the current international English fluid features still pose new and new questions related to, inter alia, terminology, translation, lexicography and teaching practice.

Among a number of terms existing for defining the English language as a means of worldwide communication for the purposes of the present study we have chosen "International English" as this term was adopted by the majority of the linguists. As a label it provides a comprehensive description of the current status of English. Thus, according to a well-known and authoritative source, an international language is:

"... a language in widespread use as a foreign language or second language, i.e. as a language of international communication. English is the most widely used international language"

(Longman Dictionary of Language Teaching and Applied Linguistics 2010: 295).

The aim of the present study is to analyse selected new words for defining specific English language forms of various origin (natural and artificial) belonging to different styles of speech. The language material (more than 200 lexical units) was selected by means of continuous sampling method applied in eight monolingual e-dictionaries, both British and American, in which new English words are registered and interpreted (Cambridge Dictionary (CamD), Collins Dictionary (ColD), Merriam-Webster Dictionary (MWD), Macmillan Dictionary (MD), Oxford Living Dictionary (OLD), Unwords Dictionary (UnD), Urban Dictionary (UrD), Word Spy (WS). For the purpose of the present study, the following definition of a neologism has been adopted:

\footnotetext{
"a new word or expression, or an existing word used with a new meaning" (Macmillan English Dictionary for Advanced Learners 2007: 1002).
}

Thus, we consider neologisms in a broad sense as words that have been coined to denote new things, concepts, etc., resulting from the development of the international language community united presently by the English language. Among them there are new official nominations (very often synonymous, or nearly-synonymous, with the already existing ones) and occasional words (nonce 
words) invented for a particular purpose or occasion for an expressive but typically laconic utterance.

The notion "new words" is conventional, as one knows that sometimes a word can be once coined, but it becomes popular - due to some circumstances or its use in an utterance of a famous person - several decades later. In our examples we sometimes indicate in parentheses the date of the registration of a new word, where a dictionary provides such information. The dates, most explicitly given in the Oxford English Dictionary and the Word Spy Dictionary, confirm that the process of gaining popularity by a new word and its registration in a dictionary can be very long.

In our previous research (Merkulova 2019) the semantics and morphology of the new words were analysed in detail and in the context of the evolution of the language under topical social and geopolitical transformations present in the world. We addressed the new realities being reflected by the English language to denote the existing variants, types of accent, dialects, etc. In the present paper a thematic classification of the new words is proposed, and their semantics and morphology are further discussed.

The evidence of the new words influx is found in a great number of coinages for describing the neologisation process itself, registration in dictionaries, relevant participants, tools, results, etc. First of all, the new words implicitly characterizing the coinages are: protologism (ColD; $\mathrm{MD}$; UnD; UrD; WS), unword (UnD), singlet (ColD; MWD; UnD), fuzzword (WS; UnD; UrD), Frankenword "awkward or unsightly" neologism (CD; MD; MWD; WS; UrD), wordnap (WS), i.e. for the "results" of their linguistic creativity.

Native and non-native English speakers who are active in coining new words are called: word-doner (UnD), lexiconista (MWD), wordetician (MWD; $\mathrm{UrD}$ ), english hacker (UrD), lexicomane (ColD; MWD), conlanger - a language constructor (ColD; MD; DMW; EOLD; UrD).

\section{New words indicating the English language domain}

In the era of globalization and the triumphant spread of English throughout the world, there have been constant terminological searches to define this phenomenon, and as a result, numerous authors' neologisms and creative coinages appeared. Among them we discern some new words for the variants of the general English language. Some researchers attribute them to the manifestations of the socalled 'linguistic imperialism' (Phillipson 1992). Dozens of the new words belonging in this group had been analysed by the authors of the present article and divided into several subgroups.

The first subgroup is represented by the neologisms Weblish, textlish, Internetese, Globish, Netspeak. All of them mean specific simplified versions of the English language, but the first two refer to the forms of English typical of online documents and messages (we call them "artificial language forms"): with 
specific use of capital and low case symbols, inaccurate punctuation, simplified spelling and grammar, informal style, etc. The emergence of these language phenomena in English was evidently due to the technological advances of the late twentieth century, such as the Internet, e-mail, electronic messaging services, social networks.

The neologism Weblish is registered in three out of the eight dictionaries subjected to analysis: Word Spy, Urban Dictionary, and The Collins Dictionary.

The Word Spy dictionary provides two excerpts from the English-language periodicals: The Sunday Times and The Daily Telegraph. In them explicitly the negative impact of this language version on English is evaluated:

Just as the government is spending about Pounds $200 \mathrm{~m}$ on a programme to reimpose the traditional rigour of literacy and numeracy, it also faces one of the greatest technological challenges to English. The internet and e-mail have already spawned their own words and grammar which has been dubbed 'weblish'. Richard Woods, "Illiterate Britain!?," Sunday Times, May 13, 2001.

The popularity of e-mail is destroying the normal rules of spelling and grammar leading to 'weblish', a lower case global language littered with mistakes, according to marketing consultancy. The Fourth Room. "The rise of the Digitally Literate," The Daily Telegraph, August 24, 2000. (https://www.wordspy.com/index.php?word=weblish [Accessed: 1st May 2018]).

The negative opinion on the word Weblish itself was expressed by the moderator and compiler of the Word Spy Dictionary P. MacFedris:

"This word is one of many that have been coined to describe the strange linguistic beast that is the English language, Internet version. By far the most popular is Netspeak, but this word has gained some currency (both as weblish and Weblish), despite its rather ugly construction (https://wordspy.com/index.php?word=weblish/notes [Accessed: 1st May 2018]).

It is worth paying attention to two specific features of the word Weblish. This approximately 20-years old word still possesses two spelling variants (Weblish/weblish) and has a "word-competitor", i.e. a synonymic expression Netspeak. David Crystal in his book Language and the Internet calls this English language variant a "computer-mediated language". The author sees, unlike many other linguists, mostly a positive impact of the Internet-based language on the future of the English language in general; he foresees a dramatic expansion in the variety of language, writing styles, and unprecedented opportunities for personal creativity, etc. (Crystal 2003). But yet both Weblish and Netspeak are considered to be not entirely natural, but rather artificial and reduced variants of the English language. Their performance variety is limited by special spheres of virtual communication.

In the Urban Dictionary, Weblish is defined as a specific slang for online communication and is illustrated as follows: 
OMG ur such a jerk! WTF is ur problem?

(https://www.urbandictionary.com/define.php?term=weblish [Accessed: 1st May 2018]).

In the Collins Dictionary Online the keyword for the Weblish definition is 'shorthand', and it is defined as a quick and easy form of English that is used in text messaging, chat rooms, etc. (https://www.collinsdictionary.com/dictionary /english/weblish [Accessed: 1st May 2018]).

If Weblish is a variant used in the Internet in general, textlish (Urban Dictionary entry) is a kind of text message in English (in this meaning synonymous with Weblish) - with numerous lingo and typo (i.e. mistakes, misspellings), for example:

ets eet. FrIdAh!!! thats how u spell it xD he told meh it durin art and alex still duznt enderstand that he duznt, ima lernin, frend, bein, i dont no, sumting, theers, textlish mks no sns (https://www.urbandictionary.com/define.php?term=textlish [Accessed: 1st May 2018]).

The neologism Globish (Global + English), found in several dictionaries (WS; $M W D ; U r D ; M D)$ is defined similarly in them, for example:

The simplified English spoken by many nonnative English speakers; a proposed form of English that uses a limited vocabulary and basic syntax to help nonnative English speakers communicate. (https://www.wordspy.com/index.php?word=globish [Accessed: 1st May 2018]).

A simplified version of English that only uses 1500 basic words and simplified grammar to facilitate communication with non-native speakers of English (https://www.macmillandictionary.com/dictiomary/Globish [Accessed: 1st May 2018]) .

The Macmillan Dictionary entry contains a commentary explaining that in the era of intensive travelling and "the huge reach of electronic media" Globish won't be enough for communication, and many people will want to learn English (https://www.macmillandictionary.com/dictionary/british/globish [Accessed: 1st May 2019]).

It is interesting to note that the research on the effect of text-messaging on Arab EFL learners' English academic writing (Al-Salman and Saeed 2017: 237) did not reveal "a heavy use of texting features, which suggests that this phenomenon neither poses a serious threat nor adversely impacts students' written English".

According to the statistical data given in the Urban Dictionary, approximately four billion nonnative speakers use Globish in their intercultural and international communication (https://www.urbandictionary.com/ define.php? term = Globish). One should pay attention that this coinage, although it indicates one of the artificial, reduced and simplified variants of an international English, is written with a capital letter, according to the rules of English spelling, in which it follows 
the convention used for other (standard) words denoting a language or a nationality.

In accordance with the theory of Braj B. Kachru, Globish is used by representatives of the "Outer" and "Expanding" Circles and serves as a lingua franca for business communication. From a linguistic point of view, Globish is similar to pidgin because of its strong tendency to accept simplification. On the other hand, it has features common with some varieties of "new variants" of English (we shall discuss them below). At the same time, Globish is not a Global English in the understanding of David Crystal, i.e. the language widely functioning in the whole world, having a certain status and most widely taught and learned (Crystal 1997: 150). Thus, on the example of the neologism Globish we can see one more case of terminological inexactitude.

The second subgroup comprises the neologisms that vividly illustrate the idea of the domination of one language, namely, English. Based on the critical paradigm, these neologisms convey the negative attitude to linguistic imperialism. These new words are: linguocentrism, i.e. "the belief that one's own ;anguage is superior to all others" (MWD); monolingualization, i.e. "the use of only one language" (MWD); ethnocentrism, i.e. "behaviour or beliefs that favour one particular culture and judge other cultures against it" (ColD; CamD; MD; EOLD; $\mathrm{UrD})$; Anglofication, i.e. "the act of making cultural or ethnic items whiter than they should be, English entitlement" (UrD), and an acronym EOP, which stands for "English Only Policy", indicating the language policy for employment and training $(M W D)$. These unofficial new words, coined by nonnative English language speakers, nevertheless, indirectly reflect the idea of other (officially adopted) new expressions: Anglosphere (anglospherism, anglospherist as its derivatives):

The collection of English-speaking nations that support the principles of common law and civil rights (https://wordspy.com/index.php?word=anglosphere [Accessed: 1st May 2018]).

The ideology of Anglosphere was formulated by James C. Bennett in his book, "An Anglosphere Primer" (Bennet 2001). The citations from it, given in the Word Spy Dictionary, clearly convey, to our mind, the idea of indissoluble links among language, culture, history, social values and customs which unite people of certain nations and exclude the people belonging to other cultural and social spheres. At the same time, this expression confirms the idea of globalization by means of the English language as an international system:

Nations comprising the Anglosphere share a common historical narrative in which the Magna Carta, the English and American Bills of Rights, and such Common Law principles as trial by jury, presumption of innocence, "a man's home is his castle", and "a man's word is his bond" are taken for granted. Thus persons or communities who happen to communicate or do business in English are not necessarily part of the Anglosphere, unless their cultural 
values have also been shaped by those values of the historical English-speaking civilization (https://wordspy.com/index.php?word=anglosphere [Accessed: 1st May 2018]).

Geographically, the densest nodes of the Anglosphere are found in the United States and the United Kingdom, while Anglophone regions of Canada, Australia, New Zealand, Ireland, and South Africa are powerful and populous outliers. The educated English-speaking populations of the Caribbean, Oceania, Africa and India constitute the Anglosphere's frontiers (https://wordspy.com/index.php?word=anglosphere [Accessed: 1st May 2018].

One more group of the new words in this category includes the names of various institutions, organizations, political events, etc. They emerged in English, and although they do not indicate directly the English language domain, at present they are used in this language in international contexts. The items belonging in this group are for example: BRICS, which stands for Brazil, Russia, India, and China (CamD; ColD; MWD; MD; EOLD; UrD; WS), Grexit (CamD, ColD, OLD, UrD, WS), Brexit (CamD, ColD, MWD, MD, OLD, UnD, UrD, WS), brexpert (MWD), Mint, standing for Mexico, Indonesia, Nigeria, and Turkey (CamD, MD), civets - Colombia, Indonesia, Vietnam, Egypt, Turkey and South Africa (CamD).

\subsection{New words for denoting the English language variants being a result of its interaction with other national languages}

The global spread of the English language as a tool of international communication has resulted in the emergence of its many variants that are used by various ethnic groups all over the world. This phenomenon has motivated profound descriptions in many linguistic works and has been classified in detail within numerous different approaches (Mühlhäusler 1986; Phillipson 1992; Trudgill, Hannah 2008; Wolf, Polzenhagen 2009; Seidlhofer 2005). The most common division is into English as a native language (mother tongue) or a nonnative language. The theory of "three concentric circles" (Inner, Outer, and Expanding) originally proposed by Kachru is supported by many scholars despite its apparent imperfectness for some context in sociolinguistics (Proshina, Eddy 2016:252). Some other well-known classifications belong to a number of researchers from different countries (Strang 1970; Strevens 1980; Görlach 1988; McArthur 1998; Modiano 1999a, 1999b; de Swaan 2002, 2013, Schneider 2003, 2007 etc.).

The functioning of the English language in each of these circles indicated by Kachru is very specific and has various consequences for the question of language interaction and mutual influence between languages and varieties, taking into consideration the former colonization of some countries and current globalization processes. The problem of the interaction between languages is topical, for example, for Europe, where the implementation of language policies within the Union faces some difficulties. These, inter alia, include: 
unprecedented language diversity [...and the fact that] in different countries "the European language policy is developing at different speeds and even in different directions, the inevitable gainer in such a situation being international English" (Mar-Molinero and Stevenson 2006: 240).

As a result of the interaction of national languages with English the new variants of the latter appeared. They are often called New Englishes (cf. Pride 1982; Foley 1988; MacArthur 1998) or World Englishes (Smith 1976; Kachru, Smith 1985; Bolton 2005; Siemund, Kintana 2008; Neumann-Holzschuh, Schneider 2000; Mukherjee 2010; Wolf 2010; Proshina 2010). In the dictionaries under consideration for the present study one can find quite many new interesting words indicating such language interrelation. For example, for two main national variants of English such as American (AE) and British (BE) the neologisms Ameriglish (UnD, UrD) and Amglish (UnD) appeared. The former is "the language spoken by the majority of the United States of America, often considered close to the original form of the English language" (http://www.unwords.com/unword/ Ameriglish.html [Accessed: 1st May 2018]). It is the variant that many people of the world choose for learning, teaching, and international communication. However, the existence of several spelling variants and differences in this word's morphology (amenglish, Amerienglish) points to the novelty of this contracted form along with traditional word-combination 'American English'. Unlike Ameriglish, the word Amglish refers to the version of the English language that is used by both the US residents and the younger generation of Great Britain. In this regard, we can make the assumption that the American variant proves to be the most preferable among the native speakers (in Kachru's Inner circle). Undoubtedly, the current English language reflects through such neologisms important geopolitical, social and cultural realities: Americanese - "American English; English which contains many Americanisms" (EOLD, UnD, UrD), anti-American - "hostile to people or ideas that are critical of the United States (WS), Americaphobia (MWD, UrD) vs. Britophilia (MWD), Britophobia (WS), Americanteer - "a follower of the America First concept, a movement for the free thinkers of the 21st Century" (UrD), etc.

Special attention should be paid to the neologisms which appeared due to the contacts of the English language and the (non-English) mother tongue within some community. Very often, the result of such contacts is the hybrid or "nativised" variants of the English language because of the simultaneous use of two languages - native and foreign (here: the English language). This subgroup from our corpus includes the words that relate to new variants of the English language (New Englishes) of the Outer and Expanding circles: Arablish, Banglish, Chinglish, Denglish (Denglisch), Farsinglish, Finglish, Hinglish, Japlish, Konglish, Manglish, Portugish, Rusglish, Singlish, Spanglish, Swanglish, Tanglish, Urlish.

These words are present in all eight dictionaries under study. Usually all of them, according to their morphology, are blends (portmanteau words), i.e. the 
combination of two bases: the name of the contacting language (Arabic, Bengali, Chinese, Farsi, Finnish, Hindi, Japanese, Korean, Malay, Portuguese, Russian, Singapore, Spanish, Swahili, Tamil, Urdu) and English, contracted by means of the apocope of the first element, and by the apheresis of the second element, but the "size" of these contractions is different and may result in the following reduced variants of the word 'English': - glish, -glisch, -lish, -ish.

Among these new words for the New Englishes there are some exceptions: Denglish - with the first element as the name of the national language - German (from 'Deutsch') and with the second element in French - Franglais (OLD, CamD, UrD). The reversed order of the elements can be seen in Engalog (MW) (English+Tagalog) - the largest cultural-linguistic group in the Philippines). Perhaps, this sequence is due to the intention to focus attention on the significant influence of English on these national languages.

Another interesting neologism is Japerican (MWD) for defining the interaction of English and Japanese. Sometimes the same word is used to indicate the simultaneous use of the two languages in speech, although the labels are not to denote a pidgin or a creole.

The registration in the dictionaries of a large number of neologisms for denoting English and a language coming into contact with it, confirms the current reality that English is a recognized international means of communication which has crossed many national borders and at present has an impact on other language systems, creating a global translingual space represented by Global Englishes. Being in contact with other languages, English itself experiences linguistic transformations under their influence. As a result, a kind of "Anglo-local" bilingualism is often formed, and new linguistic practices (switching language codes, interference of grammatical and lexical systems, etc.) occur.

Some people, due to their profession, communication needs, national background, education and other significant social conditions acquire ability to use more than one language for communication, to switch from one language code to another. This linguistic phenomenon present in various communities has been recognized and denoted in lexis, e.g.: polyglossia (MWD, OLD), being an adjective synonymous to multilingualism, and in some contexts for polyglot (https://en.oxforddictionaries.com/definition/diglossia__Accessed: 1st May 20181), hyperpolyglot (MWD, ColD), translanguaging (MWD), etc.

One more interesting example from the words of this subgroup is heterodiction (MWD), typically referring to the implied necessity to switch from the native language to another one, using an e-dictionary in the context where the speaker does not really know the language itself:

When you travel to another country, prepare for heterodiction by taking a translation dictionary with you (http://nws.merriam-webster.com/opendictionary/newword_search.php [Accessed: 1st May 2018]). 


\subsection{New English words for naming accents, dialects, types of slang}

In a manner similar to the words for new variants of English being a result of its contact with other natural languages (the so-called new Englishes), a special category of new words for describing verbally some specific features of accents, dialects, slang, social variants of speech has been defined. Most of such words appeared under complex sociolinguistic conditions due to a kind of "democratization" of the classical linguistic standards, globalization, and the English language spread in multinational and multicultural communities.

Probably the best and the most illustrative environment for the coinage and the development of words within this category is modern London as a polyethnic conglomerate. There are about fifty ethnic communities with a population of more than 10,000 people, with about three hundred dialects (Berson 2011: 39). Multicultural London English (MLE) is a category to refer to their speech. MLE variety includes elements of the Caribbean, South Asian languages, specific features of the African version of the American language and of traditional London speech. The main speakers of $M L E$ are representatives of the younger generation. The definition of this new manner of speech, with specific pronunciation, simplified grammar, etc., is given in e.g. the Cambridge Dictionary, theMacmillan Dictionary, and the Urban Dictionary.

A characteristic language situation in such a multicultural and multinational country as the United States is reflected in a number of new, or relatively new, words, e.g. Ebonics (MWD, CD, UrD, OLD, WS), Southonics (MWD), Bubbonics (WS). All of them, according to their morphology ( $\mathrm{x}+$ phonics, the science of sounds), indicate, first of all, the phonetic features of American English as spoken in the West African and Caribbean regions, in the southern states of the USA ( $b u b b a$ being a southern slang). These words function as synonyms for the already existing terms, such as African American or African-American Vernacular English (AAVE).

Another interesting group of new words was coined for describing a very vivid speech phenomenon - that of the imitation of accents and language elements: Englishification, i.e. "the alteration, while speaking a language other than English, of an English word to make it sound like a word in the language one is speaking, or attempting to speak" (UnD), Jafaican (fake+Jamaican, synonym of MLE) (ColD, MD, UrD, WS), blaccent - "a manner of speaking in which one sounds like an African-American from "da hood" (MWD, UnD, UrD), imaccentate - "the act of subconsciously imitating the accent of the person to whom one is speaking, thereby causing the person to first become puzzled, and then slightly offended when they come to believe they are being made fun" (UnD), schnelling - "the act of adding a comically bad German accent; Injecting the following words or nonwords into conversation: "yah, unst, dah, isnt, yavol, uber, dost", etc.; Adding a ' $z$ ' sound to any noun" (UnD) to produce comic imitation of a German accent in English. 
Many of the listed speech features are typical of an unofficial, informal style and are often used in slang. The latter, as a kind of "oral" speech, is of particular importance in the context of the international spread of the English language. Recently, the following neologisms belonging to this group of words have appeared: slangulage (MWD) or slanguage (ColD, EOLD, UrD), i.e. "a language using slang"; slanglish, i.e. "slang talk in English" (ColD); slanguish (MWD); slanger, i.e. "a man who used slang" (MWD); slangtionary, i.e. "a book or other reference method that defines slang" (from slang + (dic)tionary) (UrD); slanguist, i.e. a "linguist who specializes in slang words and phrases" (WS); jargonaut, i.e. "a person who uses an excessive number of jargon terms when speaking or writing" (WS, UrD). Due to the patterns used while forming them, their meaning is quite transparent for a competent user of the English language.

In classifying our group of neologisms we included in this subgroup new words used to characterize the specific social accents heard in an international political and professional discourse, e.g.: pubilect, being "a dialect unique to teenagers" (WS), neurobabble, i.e. a "neurological jargon used inaccurately or simplistically" (WS), designer-babble, i.e. "a florid and jargon-filled writing style used by designers and architects" (WS).

The expression lavender language illustrates the new lexical unit for one of the social dialects - the words, phrases and ways of speaking typical of sexual minorities (LGBTQ). Currently, this speech style is intensely studied in the frameworks of lavender linguistics (William Leap's term) as a wide range of language practices in various LGBTQ international communities. 'Language,' in this context, may refer to any aspect of spoken or written linguistic practices, including speech patterns and pronunciation, specific vocabulary (Swann et al. 2004). Sometimes lavender language is understood as an elaborate alternative lexicon such as Polari.

The representatives of LGBTQ speech communities coin new words and try to redesign the English grammar in order to avoid, for example, direct gender reference. As it was found in our research, among the new words the dictionaries register the so-called "new pronouns". These include the following: $h u$ (MWD, $\mathrm{UnD}$ ), hir (instead of her and him) (MWD, UrD), shi (him or her) (UrD), heshe (MWD; ColD; UrD), i.e. a number of gender-neutral personal pronouns represented with unconventional spelling, as well as new forms referring to a third gender, or gender-fluid. In contrast, a gender-oriented idea is conveyed by a neologism Menglish (WS), meaning "[1]anguage used of, by, to, and about men (https://wordspy.com/index.php?word=menglish [Accessed: 1st May 2018]).

\section{New words and their morphological structure}

It is worth noting that a great variety of the analyzed new words in order to describe new language reality in a peculiar way conditioned the emergence of interesting lexical innovations. Some of them are sets of synonymous, or nearly- 
synonymous expressions formed through conversion (e.g. to acronym, to acronize, to acronomize (MWD), some are formed by derivation through adding of the suffix -onym (from the Greek word 'name'). This suffix is very productive for coining neologisms that appear in current English for a detailed differentiation of meaning or to particularize a sphere of application, for example: textonym (ColD; CamD; MD; UrD), webcronym (MWD; UrD), chatcronym (MWD;UrD), which are acronyms used in short, connected communications, including email, SMS, forum postings, in-game chat, etc., phantonym, being a "ghost word" which "looks like it means a particular thing but in fact means something different", (ColD; MD; MWD).

Morphological characteristics of the words under study were analysed in order to provide a deeper insight into their structure dependent on the meaning of the constituent morphemes, both lexical and grammatical ones. A word-building process is significant for understanding the principles of making new words. In the pursuit of our research goals, we focused our attention on the productivity of various world-building patterns, but also paid attention to the types of neologisms, according to the classification accepted by R. Quirk, E. Dubenets and V. Adams (Quirk 1972; Dubenets 2010; Adams 1993). In terms of their criteria and our own data we revealed that $10 \%$ of the analyzed words belonged in the category of semantic neologisms (i.e. the already known words that underwent a change in their meaning, e.g. dreamer, referring to "a person who has lived in the US without official authorization since coming to the country as a minor but who meets certain conditions that make him or her eligible for special immigration status" (ColD), mint (Mexico, Indonesia, Nigeria, and Turkey), denoting a group of countries with the potential to realize rapid economic growth (CamD), they, as used with singular antecedents of an unknown or unspecified gender, people with non-binary gender identities (https://languages.oup.com/word-of-the-year/2015-shortlist/, [Accessed: 1st May 2018] etc.). Among them, there are only few terminological new words (e.g. translanguaging, polyglossia). There are proper neologisms (the words with a new meaning and a new form, for example: MLE (Multicultural London English), referring to a dialect of English that is spoken in urban areas of the UK, especially London, and is influenced by the accents of several other languages (CamD), Americanteer, to indicate a follower of the America First concept, a movement for the free thinkers of the 21 st Century (UrD), conlanger, which refers to someone who creates constructed languages (MD), wordish, describing an unword used in speech that resembles existing words (UnD), wordrobe, referring to a person's vocabulary (UrD), lexiconista, referring to one who enjoys dictionaries, words, and the development of new words (MWD), etc.. Such words were found to be the most numerous and amounting to $90 \%$ of the whole corpus. As for the parts of speech represented in the corpus, our research revealed that $93 \%$ of all analyzed lexis were nouns, $4 \%$ of the words were adjectives, and $3 \%$ were verbs. 
New words in general, as in entire English lexicon outside our corpus, can be formed mainly by means of derivation, abbreviation and blending, conversion, back formation, and compounding, the latter being the most productive and popular process of them all. The graphic representation of the research study results related to neologisms resulting from the global spread of English can be seen in Figure 1 below.

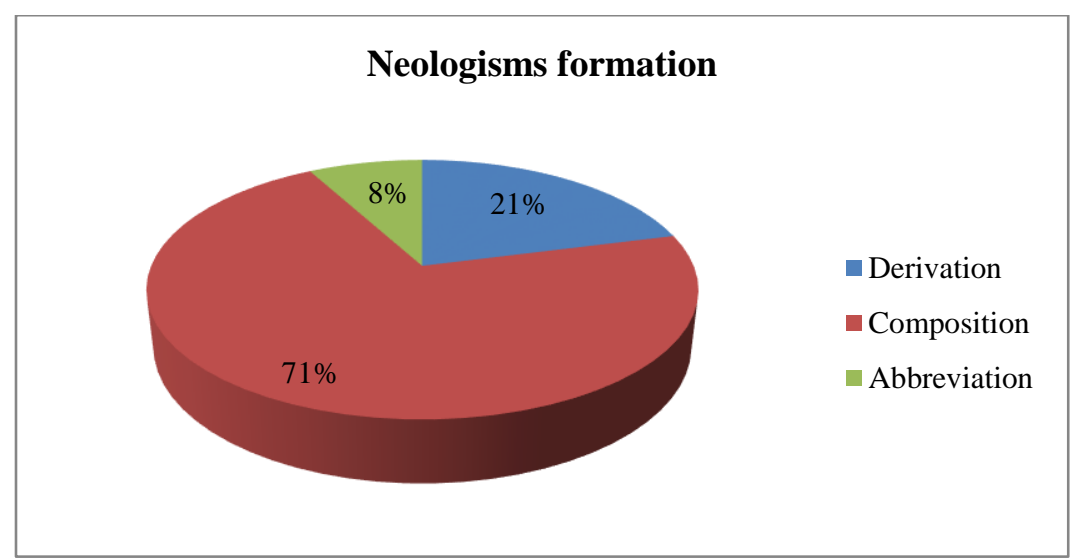

Figure 1: The main processes of word formation in the group of neologisms under analysis

Our study of new lexis on the basis of our research corpus has shown that compounding of various types is the most productive and widespread way of word formation. This trend correlates with the results of other researches (cf. e.g. Zabotkina 1989).

According to their morphological structure, the new words can be subdivided into: proper compound words, which contain two stems, and compound-affixed words, where besides the stems there are affixes; and compound-contracted words (see Table 1). Among the syntactic type of the new words the category of blends dominates in number (cf. the examples below).

A compound-contracted word can often be formed as a combination of apocope of the first element and apheresis of the second one, for example, glocalization (global+local+affix) (CamD; ColD; MWD; MD; EOLD; UrD; WS), Amglish (American + English) (UnD), blaccent (black+accent) (MWD; $\mathrm{UnD}$; UrD), slangulage (slang+language) (MWD), etc. Among them the leading groups are the compound words of a neutral type (e.g. Americaphobia (America+phobia), heterodiction (hetero+diction), or of (what was dubbed here) a morphological type (globophobe, linguocentrism, Britophilia, Britophobia). 
An interesting category is the group of compound words of the morphological type referred to as neoclassical compounds by V. Adams (Adams 1993). Such neologisms usually contain morphemes, which are Latin or Greek in origin. In our examples such words constitute $14 \%$ of the corpus. Among affixed words there are neologisms with class-maintaining prefixes, such as: trans-, anti-, hyper-, proto-, etc. of Greek and Roman origin). Such suffixes do not change the word class but change the meaning of the words which are modified by them. Some neologisms under study were formed by means of class-changing derivational affixes. They change the word class to which they can be added e.g. (Americanteer (noun) < American (adjective) + teer; Globalista (noun) < global (adjective) + ista; Englishification (noun) < English (adjective) + -ification; molingualization (noun) < monolingual (a compound adjective) + -ization).

The least productive way of word formation in our research corpus was abbreviation, including acronymy. The study identified names of institutions and organizations which should be read as individual letters (typical acronyms), e.g., $E O P, M L E$, and acronyms in the narrower sense, where the coinage is pronounced as an individual word, e.g. MINT (or mint): Mexico, Indonesia, Nigeria, and Turkey. The relevant data has been shown in Table 1.

Table 1: The data on the compound words according to their structure (\%)

\begin{tabular}{|c|c|c|c|c|c|}
\hline \multicolumn{6}{|c|}{ Compounding } \\
\hline \multirow{2}{*}{$\begin{array}{c}\text { Compound } \\
\text { words proper }\end{array}$} & \multirow{2}{*}{$\begin{array}{l}\text { Compound- } \\
\text { affixed } \\
\text { words }\end{array}$} & \multicolumn{4}{|c|}{ Compound-contracted words } \\
\hline & & Blends & $\begin{array}{l}\text { Apocope } \\
\text { of the } \\
\text { first stem }\end{array}$ & $\begin{array}{c}\text { Apheresis } \\
\text { of the second } \\
\text { stem }\end{array}$ & Incorporation \\
\hline $15 \%$ & $9 \%$ & $51 \%$ & $4 \%$ & $15 \%$ & $6 \%$ \\
\hline
\end{tabular}

As can be deduced from the data given in Table 1, compound-contracted words constitute the majority and are subdivided into four subgroups: blends, i.e. words formed from a word groups (Japerican < (Japanese + American); words where the first stem is abbreviated by means of apocope (blaccent < (black + accent); words with the second stem abbreviated by means of apheresis (slanguist $<$ (slang + linguist); and incorporation (Jafaican < (fake+Jamaican). It is evident that the tendency to contract and blend relates to one of the main linguistic laws, that of economy of effort.

In the analyzed dictionaries, among English neologisms some loan words and fragments of foreign words were found. This group of new words is not numerous 
in our research corpus, but it is of special interest as these new words often indicate peculiar borrowings from German and Spanish into English. These neologisms represent some examples of derivation but by means of foreign prefixes or suffixes. For instance, we have the word Shnelling, being a combination of the German word schnell (meaning quick) and the English morpheme -ing, or a German prefix - uber/über (two variants of spelling), which combines with nouns and adjectives to form nouns and adjectives that refer to a great or extreme example or instance of a thing, or a quality of something as in uberize or uberorgastic (https://www.collinsdictionary.com/dictionary/english/uber [Accessed: 1st May 2018]). A currently productive Spanish noun-forming suffix -ista can be used to describe someone who is a strong supporter of another person, or an idea mentioned in the first morpheme of the word (https://dictionary.cambridge.org/dictionary/english/ista [Accessed: 1st May 2018]), cf. globalista - a very cosmopolitan and well-travelled person (CamD), lexiconista - one who enjoys dictionaries, words, and the development of new words, (MWD).

\section{Conclusions}

One of the topical issues of modern linguistics is the study of languages in interaction, the prospects of their further developments in the context of close international interaction, ongoing mutual enrichment and often simplification, as it is currently the case with the English language. For various reasons, both linguistic and extralinguistic, English became the language of international communication, and this, in turn, has led to its neologisation. The new vocabulary in its richness reflects the dynamicity of linguistic changes in the newly-emergred varieties of the English language, the transformations in selected traditional elements of its lexical and grammatical as well as phonetic and spelling systems.

The present paper demonstrates selected results of the study based on the data culled from eight dictionaries, the data including selected new English words reflecting the international status of the English language. The study contains their thematic, semantic and morphological characteristics. The discussion of the semantics of the neologisms points to the fact that new lexis tend to emerge under the influence of changing political, social and cultural realities of the world and the life of the English language users belonging in different communities. The representatives of such communities seek means of expression for refernce to and naming of new phenomena, or, quite often strive to provide means of expression for new meanings and connotations related to the already known phenomena. In such contexts many creative and partly synonymous expressions (cf. the linguistic redundancy law) appear: some of them are gradually assimilated within the language, become registered in relevant dictionaries, and made to enter the core English vocabulary. 
The morphological analysis of the new words based on the data from our experimental corpus revealed no significant novelty involved in the process of the coining of the new words. Various conventional means of word-formation and typical morphological patterns had mainly been used, and quite expectedly, compounding proved to be the most productive process within the corpus. Formation of blends as the reflection of the general tendency related to the strategy of "condensation" for expressing new notions, processes, phenomena, etc. by a single word but not by a word combination correlated with another basic linguistic law - that of economy of effort.

In general, it is evident that the conducted research, and the methodology proposed in the paper, proved able to provide an insight into various cognitive mechanisms involved in "naming for a better understanding", for further interpretation and discourse analysis, as well as for novel researches in neography.

\section{References}

Adams, Valerie. 1993. An Introduction to Modern English Word-formation. London: Longman.

Al-Salman, Saleh M. and Aziz T. Saeed. 2017. Effects of Text-messaging on the Academic Writing of Arab EFL Students. Research in Language 15(3), 237-252. https://doi.org/10.1515/rela-20170014

Bennett, James C. 2001. An Anglosphere primer. Presented to Foreign Policy Research Institute. Available from: https://www.explorersfoundation.org/archive/anglosphere_primer.pdf [Accessed: 1st May 2018].

Berson, Alexandra B. 2011. "London model" of multicultural development: urban administrative initiatives and cultural integration of ethnic minorities. Vestnik Rossijskogo Universiteta Druzhby Narodov: Seriya Mezhdunarodnye Otnosheniya, 3, 37-50.

Bolton, Kingsley. 2005. Where WE stands: Approaches, issues and debate in world Englishes. World Englishes, 24(1), 69-83. https://doi.org/10.1111/j.0883-2919.2005.00388.x

Cambridge Dictionary. [Online] Available from: https://dictionary.cambridge.org/ [Accessed: 1st May 2018].

Globish. 2008-2018. [Online] Available from: http://www.globish.com/?page=about_globish\&lang [Accessed: 14th May 2018].

Collins Dictionary. [Online] Available from: https://www.collinsdictionary.com/ [Accessed: 14th May 2018].

Crystal, David. 1997. English as a Global Language. Cambridge: CUP.

Crystal, David. 2003. Language and the Internet. Cambridge: CUP.

Dubenets, Elvina, M. 2010. Sovremennyjy angliyskiy yazik. Lexicology. M: Glossa-Press.

Firth, Alan. 1996. The discursive accomplishment of normality: on 'lingua franca' English and conversation analysis. Journal of Pragmatics, 26, 237-259. https://doi.org/10.1016/03782166(96)00014-8

Foley, Joseph. 1988. Introduction to New Englishes: The Case of Singapore. Singapore: Singapore University Press.

Görlach, Manfred. 1988. The development of Standard English. In Manfred Görlach (ed.), Studies in the History of the English Language, 9-64. Heidlberg: Carl Winter.

Halliday, M.A.K., McIntosh, Angus and Peter Strevens. 1964. The Linguistic Sciences and Language Teaching. London: Longmans. 
House, Juliane. 1999. Misunderstanding in intercultural communication: Interactions in English as a lingua franca and the myth of mutual intelligibility. In Claus Gnutzmann (ed.), Teaching and Learning English as a Global Language. 73-89. Tübingen: Stauffenburg.

Jenkins, Jennifer. 2009. English as a Lingua Franca: interpretations and attitudes. World Englishes, 28(2), 200-207. https://doi.org/10.1111/j.1467-971X.2009.01582.x

Kachru, Braj, B 1986. The alchemy of English: the spread, functions, and models of non-native Englishes. Oxford: Pergamon Press.

Kachru, Braj, B. and Larry E. Smith. 1985. Editorial. World Englishes, 4(2), 209-212. https://doi.org/10.1111/j.1467-971X.1985.tb00408.x

Kirkpatrick, Andy. 2010. The Routledge handbook of World Englishes. London/New York: Routledge. https://doi.org/10.4324/9780203849323

Kirkpatrick, Andy. 2011. English as an Asian lingua franca and the multilingual model of ELT. Language Teaching, 44(2), 212-224. https://doi.org/10.1017/S0261444810000145

Longman Dictionary of Language Teaching and Applied Linguistics. 2010. Jack C. Richards, Richard Schmidt (eds.) Harlow: Pearson.

Macmillan Dictionary. [Online] Available from: https://www.macmillandictionary.com/ [Accessed: 14th May 2018].

Macmillan English Dictionary for advanced Learners. 2007. Macmillan: Macmillan Education.

Mar-Molinero, Clare and Stevenson Patrick. (ed.) 2006. Language Ideologies, Policies and Practices: Language and the Future of Europe (Language and Globalization). Basingstoke, UK, New York, USA. Palgrave Macmillan. https://doi.org/10.1017/S0261444810000145

McArthur, Tom. 1998. The English Languages. Cambridge: CUP. https://doi.org/10.1017/9780511621048

McKay, Sandra Lee and Wendy D. Bokhorst-Heng. 2017. International English in its sociolinguistic contexts, towards a socially sensitive EIL pedagogy. New York: Routledge. https://doi.org/10.4324/9781315092553

Merriam-Webster Dictionary. [Online] Available from: https://www.merriam-webster.com/ [Accessed: 31st July 2018].

Merkulova, Nadezhda. 2019. Novaya leksika dlya nominacii anglijskogo yazyka kak mezhdunarodnogo (na materiale odnoyazychnyh elektronnyh slovarej). [Online] Ivanovo. Available from: http://www.psu.ru/files/docs/science/dissertatsionnyesovety/merkulova/disser-Merkulova.pdf [Accessed: 1st Seprember 2019].

Modiano, Marko. 1999 a. International English in the global village. English Today, 15(2),. 22-28. https://doi.org/10.1017/S026607840001083X

Modiano, Marko. 1999 b. Standard English(es) and educational practices for the world's lingua franca. English Today, 15(4), 3-13. https://doi.org/10.1017/S0266078400011196

Mühlhäusler, Peter. 1986. Pidgin and Creole Linguistics. Oxford: Basil Blackwell.

Mukherjee, Joybrato. 2010. The development of the English language in India. In Andy Kirkpatrick (ed.), The Routledge handbook of world Englishes, 167-180. London/New York: Routledge.

Neumann-Holzschuh, Ingrid and Edgar W. Schneider. 2000. Degrees of restructuring in Creole languages. Amsterdam/Philadelphia: John Benjamins publishing company. https://doi.org/10.1075/cll.22

Oxford Living Dictionary. [Online] Available from: https://en.oxforddictionaries.com/ [Accessed: 1st July 2018].

Phillipson, Robert. 1992. Linguistic Imperialism. Oxford: OUP.

Pride, John. B. 1982. New Englishes. Rowley, Mass.: Newbury House.

Proshina, Zoya. 2010. Slavic Englishes: education or culture? In Andy Kirkpatrick (ed.), The Routledge handbook of world Englishes, 299-315. London/New York: Routledge.

Proshina, Zoya and Anna A. Eddy. 2016. Russian English (history, functions and features). Cambridge: Cambridge University Press. https://doi.org/10.1017/CBO9781139683623

Quirk, Randolf, et al. 1972. A Grammar of Contemporary English. London: Longman. 
Schneider, Edgar W. 2003. The dynamics of New Englishes: From identity construction to dialect birth. Language, 79(2). 233-281. https://doi.org/10.1353/lan.2003.0136

Schneider, Edgar W. 2007. Postcolonial English: Varieties around the World. Cambridge: CUP. https://doi.org/10.1017/CBO9780511618901

Seidlhofer, Barbara. 2005. Key concepts in ELT. English as a lingua franca. [Online] ELF Journal 59(4). 339-340. Available from: http://eltj.oxfordjournals.org/content/59/4/339.full.pdf. [Accessed: 1st Seprember 2018]. https://doi.org/10.1093/elt/cci064

Siemund, Peter and Noemi Kintana. (ed.) 2008. Language contact and contact languages. Amsterdam/Philadelphia: John Benjamins Publishing Company. https://doi.org/10.1075/hsm.7

Smith, Larry E. 1976. English as an International Auxiliary Language. RELC Journal, 7(2), 38-42. https://doi.org/10.1177/003368827600700205

Smith, Larry E. 1981. English as international language. In Larry E. Smith (ed), Readings in English as an international language, 1-8. London: Pergamon Press.

Strevens, Peter. 1980. Teaching English as an International Language. Oxford: Pergamon Press.

Strang, Barbara M.H. 1970. A History of English. London: Methuen.

Swaan, Abram de. 2002. The World Language System: A Political Sociology and a Political Economy of Language. Cambridge: Polity.

Swaan, Abram de. 2013. Language systems. In Nikolas Coupland (ed.), The Handbook of Language and Globalization, 56-76. Madlen: Blackwell.

Swann, Joan, et al. 2004. A dictionary of sociolinguistics. Endinburgh: Edinburgh University Press.

Trudgill, Peter and Jean Hannah. 2008. International English: A Guide to Varieties of Standard English. London/New York: Routledge.

Unwords Dictionary. [Online] Available from: http://unwords.com/ [Accessed: 31st July 2018].

Urban Dictionary. [Online] Available from: https://www.urbandictionary.com/ [Accessed: 31st July 2018].

Wolf, Hans-Georg and Frank Polzenhagen. 2009. World Englishes: A Cognitive Sociolinguistic Approach. Berlin/New York: Walter de Gruyter. https://doi.org/10.1515/9783110199222

Wolf, Hans-Georg. 2010. East and West African Englishes: differences and commonalities. In Andy Kirkpatrick (ed.), The Routledge handbook of world Englishes, 197-211. London/New York: Routledge.

Word Spy Dictionary. [Online] Available from: https://www.wordspy.com/ [Accessed: 14th May 2018]. 